\title{
Organized Frequency Structure of Electrocardiogram During Long-Duration Ventricular Fibrillation Under Experimental Conditions
}

\author{
DOI: $10.17691 / \mathrm{stm} 2016.8 .3 .04$
}

Received January 12, 2016

\section{M.I. Guryanov, MD, DSc, Professor, Department of Basic and Specific Medical Sciences, Faculty of Medicine}

Saint Petersburg State University, 7/9 Universitetskaya naberezhnaya, Saint Petersburg, 199034, Russian Federation

The aim of the investigation is to study the frequency structure of electrocardiogram (ECG) during long-duration ventricular fibrillation $(V F)$ in the canine heart using fast Fourier transform in the frequency range of $1-40 \mathrm{~Hz}$.

Materials and Methods. ECG has been recorded in 10 dogs before VF and during VF. No pathological changes were revealed on ECGs before VF. The VF was induced by a brief $(2 \mathrm{~s})$ application of alternating current $(30 \mathrm{~V} ; 50 \mathrm{~Hz})$ to the heart region. Spectral analysis of ECG in VF was carried out using fast Fourier transform in five frequency bands: very low frequencies $(1-3 \mathrm{~Hz})$, low (4-7 Hz), middle $(8-12 \mathrm{~Hz})$, high $(13-17 \mathrm{~Hz})$, and very high frequencies $(18-40 \mathrm{~Hz})$. Spectral power (amplitude) and specific gravity of oscillations were determined in all five frequency bands.

Results. ECG in VF is characterized by dominant frequency structure. At minute 1 of VF the most significant changes have been observed in the frequency structure with transition from domination of high frequency oscillations $(13-17 \mathrm{~Hz})$ to domination of middle frequency oscillations $(8-12 \mathrm{~Hz}$ ) and after that to domination of low frequency oscillations $(4-7 \mathrm{~Hz})$. At minutes 2-10 of VF domination of low frequency oscillations is replaced by domination of low and middle frequency ones. Total spectral power of oscillations in the range of $1-40 \mathrm{~Hz}$ shows insignificant changes at minute 1 of VF and significantly decreases at minutes 12-10 of VF.

Conclusion. Dominant frequency structure points to indicates electrical activity in VF. The results of the paper can be used in algorithms for automatic detection of VF with dominant frequency structure. Organized activity in VF provides a good theoretical framework to search for a new method of sequential rhythmic defibrillation using a series of relatively weak but rhythmic organized stimuli.

Key words: ventricular fibrillation; frequency structure of electrocardiogram; dominant frequency structure of electrocardiogram.

In contrast to coordinated heart beats ventricular fibrillation (VF) is characterized by uncoordinated contractions of separate groups of myocardial fibers unable to maintain blood circulation; VF leads to quick death unless halted by electrical defibrillation [1]. VF is a major cause of sudden cardiac death all over the world [2, 3] leading to $200,000-400,000$ deaths every year in Russia [4] and 3-7 million deaths worldwide [5].

Researchers in different fields of science, including physicists, biophysicists, mathematicians and physiologists, have traditionally described VF as a turbulent process and studied VF using complicated mathematical tools in the context of chaos and nonlinear system theories [6-11]. Meanwhile myocardial mapping has revealed organized electrical activity at the first $2 \mathrm{~min}$ [12-14]. It should be noted that mapping covers no more than $20 \%$ of ventricular myocardium while fibrillation involves the whole myocardium. It is not clear to what extent the results of mapping are applicable to the whole myocardium in VF. Besides, quantitative parameters of organized activity have not been determined under mapping in VF. These parameters could be used for VF diagnostics.

Electrocardiogram (ECG) reflects global electrical activity of the heart and provides assessment of activity of the whole myocardium in VF $[13,15]$. Spectral analysis of ECG in VF using fast Fourier transform (FFT) allows us to determine frequency content of ECG oscillations. Babsky et al. [16] were the first to carry out spectral analysis of ECG in VF using FFT. However, only one (dominant) oscillation frequency of VF was studied in this and subsequent articles [16-19]. Total frequency content of ECG in VF was not quantitatively analyzed anywhere. Total frequency range of oscillations generated by myocardium in VF can be covered using FFT analysis of ECG in a wide frequency range of $1-40 \mathrm{~Hz}$, which gives the possibility to study frequency structure and dynamics of VF. We have found no papers where frequency structure of ECG has been studied in a wide frequency range of 1-40 Hz using modern technologies of automated FFT analysis of ECG in VF.

For contacts: Marat I. Guryanov, e-mail: mgurianov@yandex.ru 
The aim of the investigation is to study the frequency structure of electrocardiogram during longduration ventricular fibrillation in the canine heart using fast Fourier transform in the frequency range of $1-40 \mathrm{~Hz}$.

Materials and Methods. Experiments on the canine heart in situ were conducted in accordance with the decree No.742 of the Ministry of Higher and Secondary Specialized Education of the USSR dated 13.11.1984, "On the Approval of Rules of Work using Experimental Animals", and the European Convention for the Protection of Vertebrate Animals used for Experimental and other Scientific Purposes adopted in Strasburg on 18.03.1986 and confirmed in Strasburg on 15.06.2006.

Ten dogs of either sex were intramuscularly anesthetized with Zoletil (20-30 mg/kg) (Virbac Sante Animale, France). After 5-7 min four electrodes for ECG recording were inserted into the forelimbs and the hind limbs of the dogs. A pair of electrodes for electrical stimulation was inserted into the chest in the region of apex cordis. In all dogs ECG was recorded using computer-based recording device NeuroS-4U (Neurobotics, Russia) at a sampling rate of $500 \mathrm{~Hz}$, filtered with $0.05 \mathrm{~Hz}$ high pass and $500 \mathrm{~Hz}$ low pass filters and stored in edf-32 format files. ECG was recorded in standard lead III. It is known that canine heart has vertical electrical axis and ECG lead III has the largest amplitude [20]. No ischemia signs were registered on ECGs before VF.

VF was induced by a brief (2-3 s) application of alternating current $(30 \mathrm{~V} ; 50 \mathrm{~Hz})$ to the chest near apex cordis region. Such electric stimulation is standard for induction of VF in the canine heart [1]. ECG was recorded during the first 10 min of VF. ECG was divided into 1-second segments and spectral analysis of these segments was carried out by FFT method using Neocortex Software (Neurobotics, Russia).

Spectral analysis of ECG in VF was carried out in five frequency bands: very low frequencies $(1-3 \mathrm{~Hz})$, low (4-7 Hz), middle $(8-12 \mathrm{~Hz})$, high $(13-17 \mathrm{~Hz})$, and very high frequencies $(18-40 \mathrm{~Hz})$. Spectral power (amplitude) and specific gravity of oscillations in all frequency bands were determined in 1-second segments of ECG as shown in Table 1. After that the same parameters

Table 1

Amplitude and specific gravity of various frequency oscillations at second 8 of ventricular fibrillation in the canine heart

\begin{tabular}{lcccccc}
\hline \multirow{1}{*}{ Oscillations } & \multicolumn{5}{c}{ Frequency (Hz) } \\
\cline { 2 - 7 } & $1-3$ & $4-7$ & $8-12$ & $13-17$ & $18-40$ & $1-40$ \\
\hline Amplitude (mV) & 0.07 & 0.08 & 0.23 & 1.16 & 0.52 & 2.06 \\
\hline Specific gravity (\%) & 4 & 4 & 11 & 56 & 25 & 100 \\
\hline
\end{tabular}

were determined for 5 -second segments of ECG ( $\mathrm{M} \pm \mathrm{m}$, $n=50$ ).

The data were statistically processed by SPSS 11.5 software for Windows using nonparametric tools: MannWhitney and Wilcoxon comparison tests, Spearman's correlation.

\section{Results}

Dominant frequency structure of VF. High frequency oscillations $(13-17 \mathrm{~Hz})$ organized to "fibrillation spindle" patterns dominated on ECG-record at seconds 5-9 of VF (Figure 1 (a)). This domination is confirmed by spectrogram (Figure 1 (b)). Middle frequency oscillations $(8-12 \mathrm{~Hz})$ also organized in "fibrillation spindle" patterns dominated at seconds 26-30 (Figure 1 (c)), which is also confirmed by spectrogram (Figure 1 (d)). Low frequency oscillations $(4-7 \mathrm{~Hz})$ dominated on both ECG-record and spectrogram at seconds 56-60 (Figure 1 (e), (f)). Apparently disorganized polymorphous oscillations of 1-20 Hz were observed on ECG-record at seconds 176-180 but spectrogram showed domination of low and middle frequency oscillations $(4-12 \mathrm{~Hz})$ over the frequency range between 1 and $40 \mathrm{~Hz}$ (Figure 1 (g), (h)).

Dominant frequency structure of VF shown in Figure 1 is true for all the dogs. High frequency oscillations took a share of $5 / 40$ in the frequency range of $1-40 \mathrm{~Hz}$ and contained $44 \%$ of total spectral power that confirms dominant frequency structure of ECG at the first seconds of VF (Figure 2 (a)). Middle frequency oscillations (a share of $5 / 40$ in the frequency range of $1-40 \mathrm{~Hz}$ ) contained $41 \%$ of total spectral power and dominated in the middle of minute 1 (See Figure 2 (a)). Low frequency oscillations (a share of $4 / 40$ ) contained $38-40 \%$ of total spectral power and dominated in the interval between the end of minute 1 (See Figure 2 (a)) and the middle of minute 2 (Figure 2 (b)). Low and middle frequency oscillations (a share of $9 / 40$ ) contained $41-61 \%$ of total spectral power and dominated in the interval from the end of minute 2 (See Figure 2 (b)) up to minute 10 of VF (Figure 2 (c), (d)).

Thus dominant frequency structure of ECG is inherent to VF in the canine heart. The first minute of $V F$ is characterized by the most significant changes in frequency structure with transition from domination of high frequency oscillations to that of middle frequency ones and then to domination of low frequency oscillations. At minutes 2-10 of VF domination of low frequency oscillations is replaced by domination of low and middle frequency ones, which reflects two-fold (from 4-7 to $4-12 \mathrm{~Hz}$ ) extension of frequency range of dominating oscillations. The change in the frequency structure of ECG oscillations is determined by oscillation dynamics during VF.

Oscillation dynamics during minute 1 of VF. Specific gravity of very low and low frequency oscillations increased at minute 1 of VF; there is strong direct correlation between duration of VF and specific gravity of very low and low frequency oscillations 


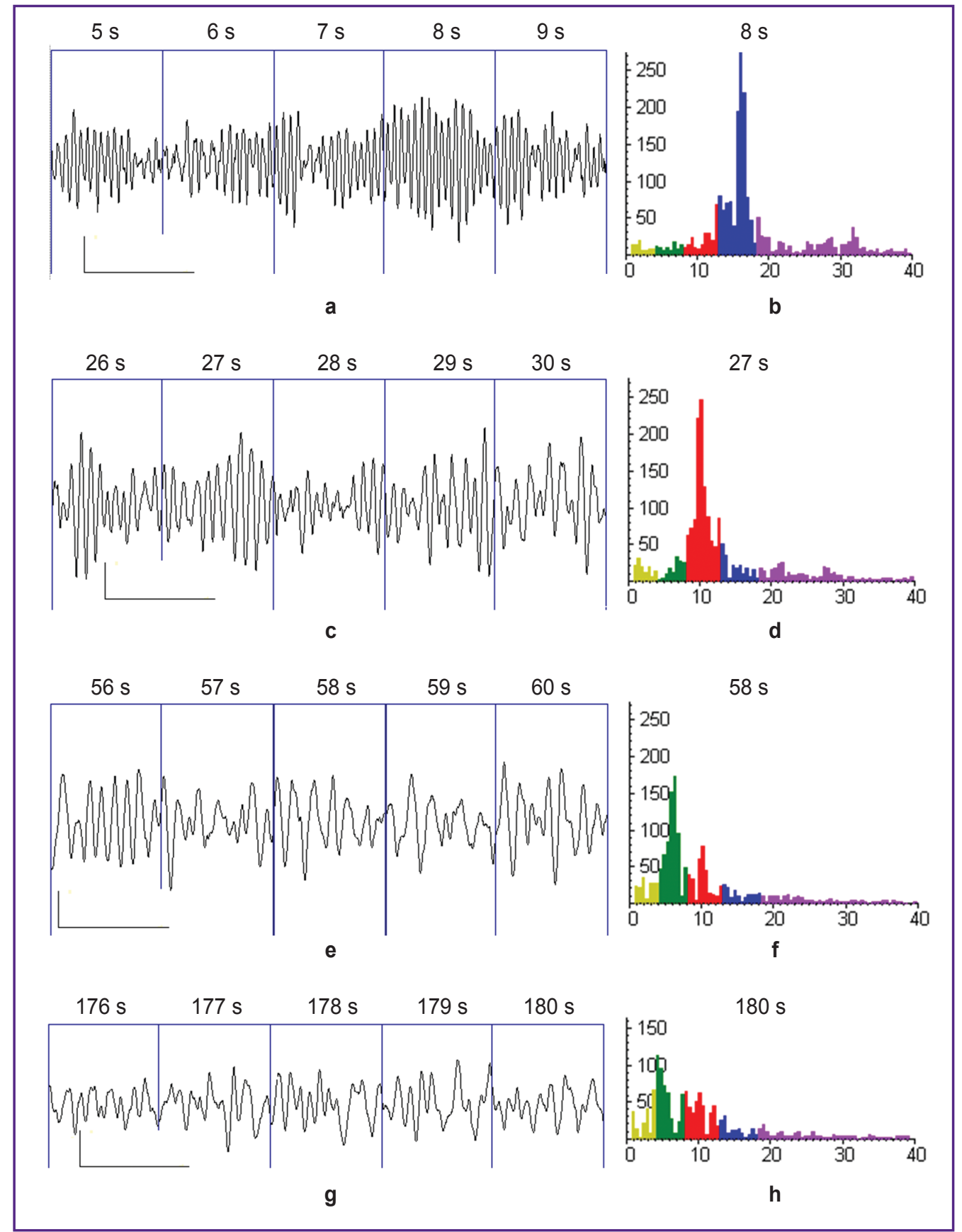

Figure 1. Five-second ECG segments (a, c, e, g) and spectrograms of one-second ECG segments $(b, d, f, h)$ at minutes $1-3$ of ventricular fibrillation in the canine heart. ECG calibration: $0.7 \mathrm{mV}, 1 \mathrm{~s}$. On spectrograms: the $\mathrm{X}$ axis shows frequency $(\mathrm{Hz}) ; \mathrm{Y}$ axis shows amplitude $(\mathrm{mV})$; colors indicate different frequency bands (1-3 Hz, khaki; 4-7 Hz, green; 8-12 Hz, red; 13-17 Hz, blue; $18-40 \mathrm{~Hz}$, violet)

(Figure $3(a)$, (b)). Specific gravity of middle frequency oscillations increased up to the middle of minute 1 and then declined (Figure 3 (c)). Specific gravity of high and very high frequency oscillations decreased; there is strong inverse correlation between duration of VF and specific gravity of high and very high frequency oscillations (Figure 3 (d), (e)).
Dynamics of specific gravity of various frequency oscillations is connected with amplitude dynamics. This is proved by strong direct correlation between specific gravity and amplitude of oscillations in all five frequency bands (Table 2).

The amplitude of very low and low frequency oscillations increased; there is strong direct correlation 


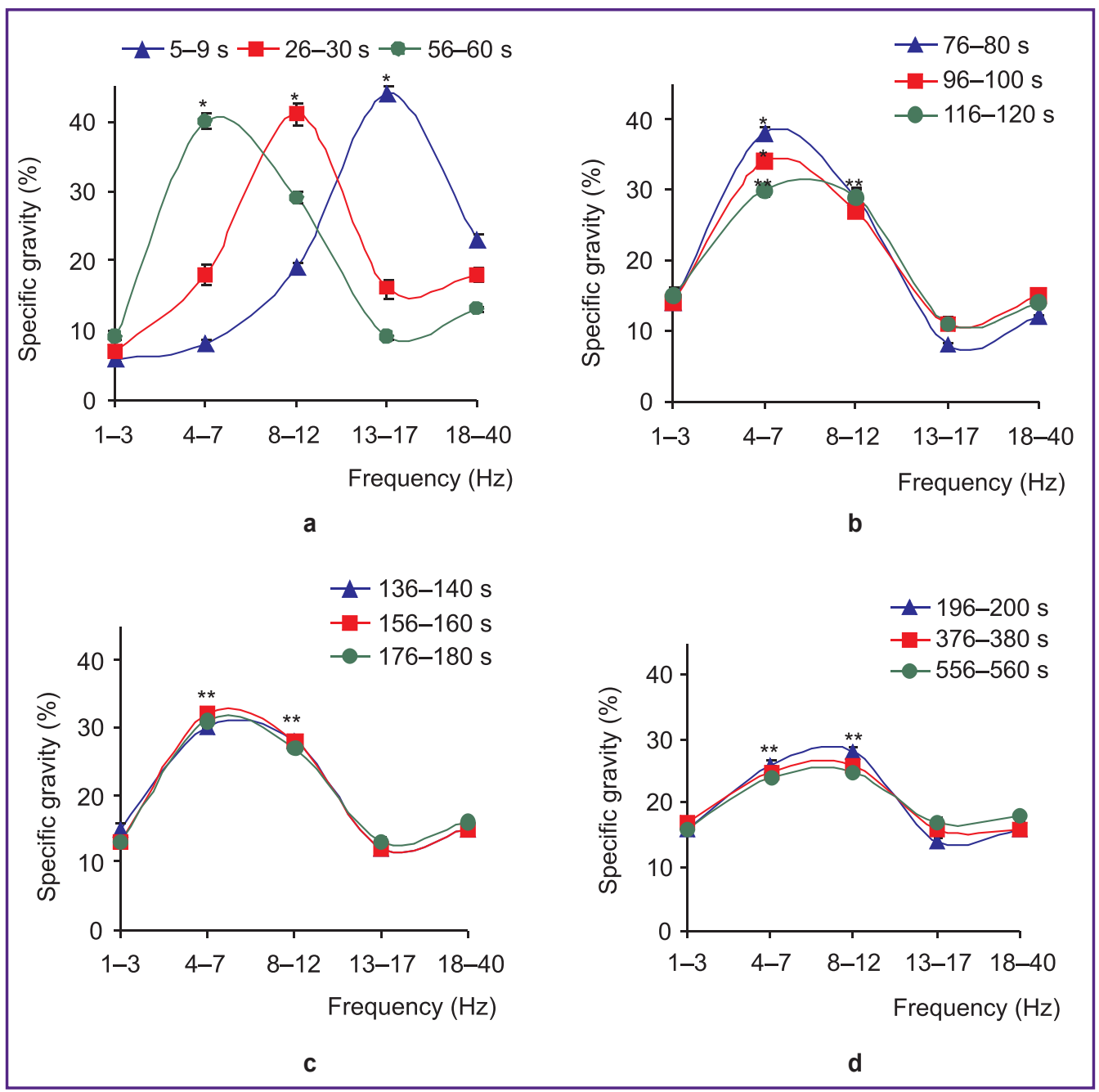

Figure 2. Specific gravity of various frequency oscillations during ventricular fibrillation in the canine heart: (a) minute 1 of ventricular fibrillation; (b) minute 2; (c) minute 3; (d) minutes 4-10; $\mathrm{M} \pm \mathrm{m} ; \mathrm{n}=50 ;{ }^{*} \mathrm{p}<0.01$ compared to other frequencies; ${ }^{* *} \mathrm{p}<0.01$ compared to $1-3,13-17$, and $18-40 \mathrm{~Hz}$

between duration of VF and amplitude of very low and low frequency oscillations (Figure 4 (a), (b)). The amplitude of middle frequency oscillations increased up to the middle of minute 1 and then declined (Figure 4 (c)). The amplitude of very high and high frequency oscillations decreased; there is strong inverse correlation between duration of VF and amplitude of high and very high frequency oscillations (Figure 4 (d), (e)). Total amplitude of oscillations in the frequency range of $1-40 \mathrm{~Hz}$ did not change significantly at minute 1 of VF (Figure 4 (f)).

Oscillation dynamics during minutes 2-3 of VF. Specific gravity of low frequency oscillations decreased at minutes 2-3 of VF; there is strong inverse correlation between duration of VF and specific gravity of low frequency oscillations (Figure $5(a)$ ). Specific gravity of high frequency oscillations increased; there is strong direct correlation between duration of VF and specific gravity of high frequency oscillations (Figure 5 (c)).
Dynamics of specific gravity of low and high frequency oscillations is connected with amplitude dynamics of these oscillations. This is proved by direct correlation between specific gravity and amplitude of low frequency oscillations $(R=0.71 ; p<0.01)$ and those of high frequency oscillations $(R=0.64 ; p<0.05)$.

Amplitude of low frequency oscillations decreased; there is strong inverse correlation between duration of VF and amplitude of low frequency oscillations (Figure 5 (b)). Amplitude of high frequency oscillations increased but did not correlate with duration of VF (Figure 5 (d)). Total amplitude of oscillations decreased; there is strong inverse correlation between duration of VF and total amplitude (Figure 5 (e)).

Oscillation dynamics during minutes 4-10 of VF. Specific gravity of various frequency oscillations did not change during minutes $4-10$ of $V F(p>0.05)$ but amplitude of oscillations decreased in all five frequency bands $(p<0.01)$; there is strong inverse correlation 


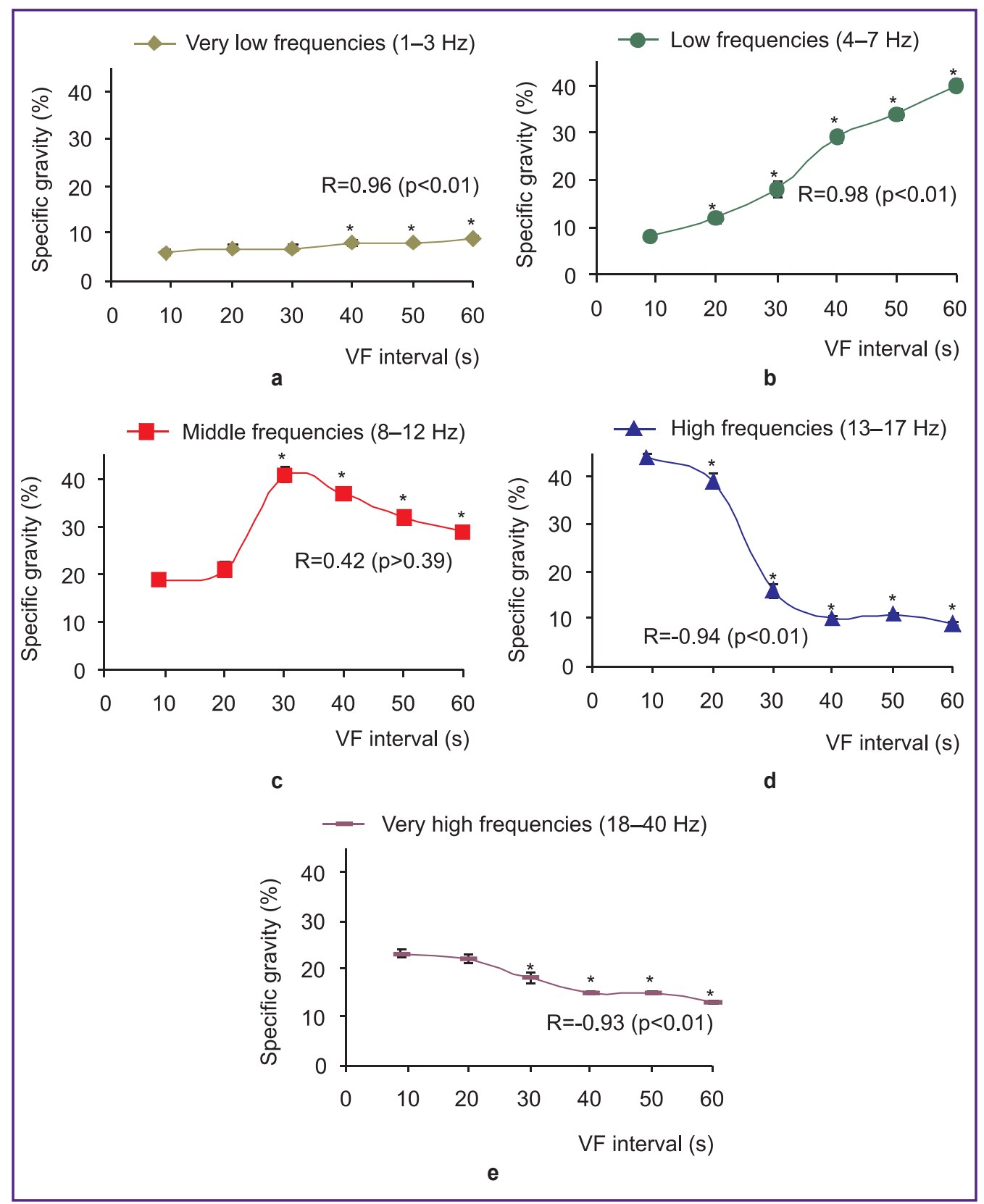

Figure 3. Dynamics of specific gravity of various frequency oscillations during minute 1 of ventricular fibrillation in the canine heart: (a) 1-3 Hz oscillations; (b) $4-7 \mathrm{~Hz}$; (c) $8-12 \mathrm{~Hz}$; (d) $13-$ $17 \mathrm{~Hz}$; (e) $18-40 \mathrm{~Hz} ; \mathrm{M} \pm \mathrm{m} ; \mathrm{n}=50$; * $p<0.05$ compared to second 9 of ventricular fibrillation; $\mathrm{R}$ : correlation between duration of fibrillation and specific gravity of oscillations

between duration of VF and amplitude of oscillations in all frequency bands (Figure 6 (a)-(f)).

Discussion. This study has revealed dominant frequency structure of ECG during minutes 1-10 of VF in the canine heart (See Figure 2). Dominant structure points to organized (synchronized) activity of myocardium. If cardiac cells generated their action potentials (APs) at random manner and independently from each other, these APs would accidentally sum up providing random total process with disorganized lowamplitude oscillations and flat spectral power density
Table 2

Correlation between specific gravity and amplitude of various frequency oscillations at minute 1 of ventricular fibrillation in 10 dogs $(p<0.01)$

\begin{tabular}{cccccc}
\hline $\begin{array}{c}\text { Oscillation } \\
\text { frequency }\end{array}$ & $1-3 \mathrm{~Hz}$ & $4-7 \mathrm{~Hz}$ & $8-12 \mathrm{~Hz}$ & $13-17 \mathrm{~Hz}$ & $18-40 \mathrm{~Hz}$ \\
Correlation & 0.97 & 0.95 & 0.98 & 0.96 & 0.98 \\
\hline
\end{tabular}

of ECG signal over the frequency range between 1 and $40 \mathrm{~Hz}$. 


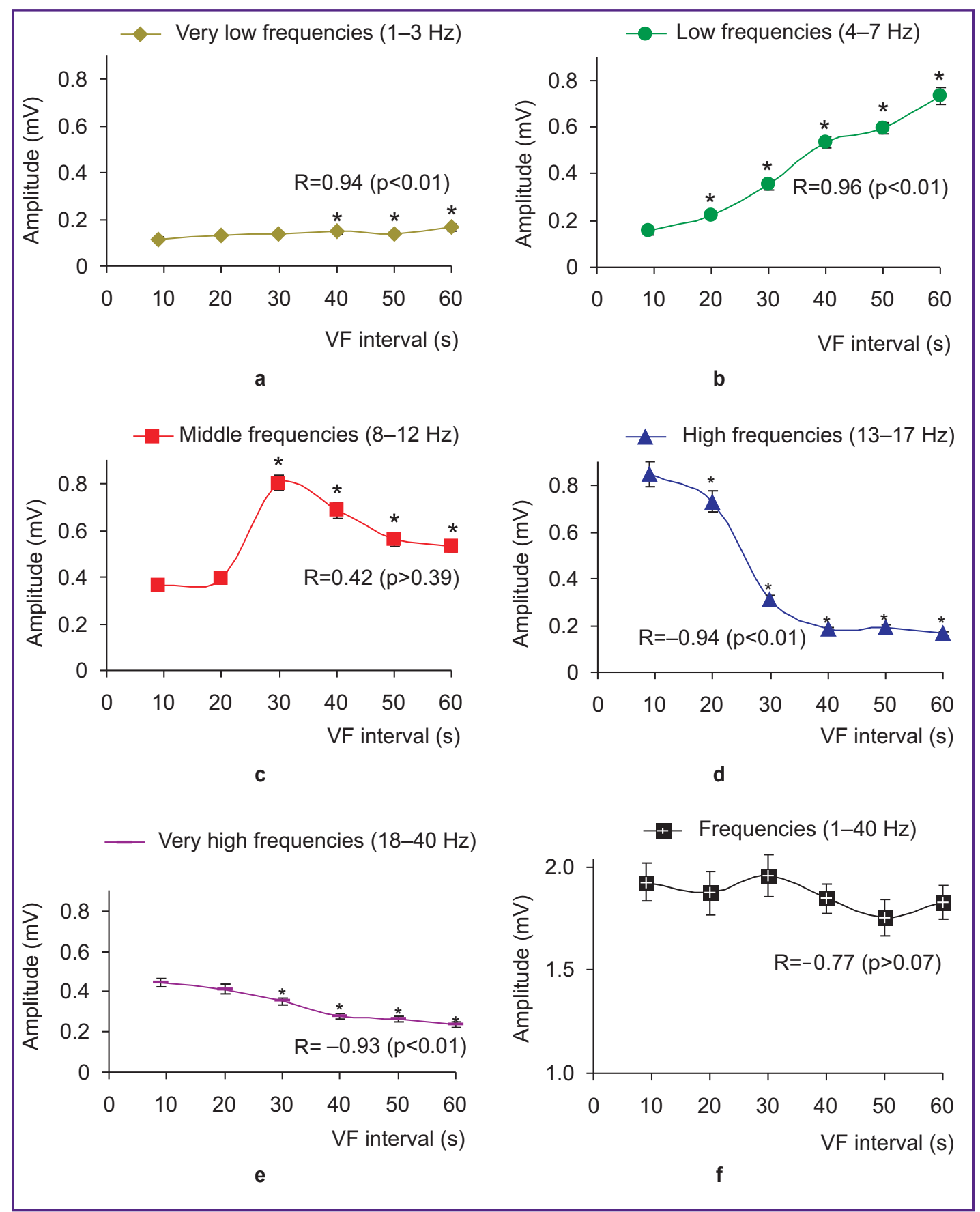

Figure 4. Amplitude dynamics of various frequency oscillations during minute 1 of ventricular fibrillation in the canine heart: (a) 1-3 Hz oscillations; (b) 4-7 Hz; (c) 8-12 Hz; (d) 13-17 Hz; (e) 18-40 Hz; (f) 1-40 Hz; $M \pm m ; n=50 ;{ }^{*} p<0.05$ compared to second 9 of ventricular fibrillation; R: correlation between duration of fibrillation and amplitude of oscillations

Domination of high frequency oscillations (See Figure 2 (a)) is likely to reflect synchronized activity of cardiomyocytes generating APs of $13-17 \mathrm{~Hz}$ and not suffering from ischemia at the first seconds of VF. When coronary perfusion was maintained during $1 \mathrm{~h}$ under VF cardiomyocytes generated APs of the same frequencies $(13-17 \mathrm{~Hz})$ as they did at the first seconds of VF [21].
Analysis of biochemical works confirms the absence of ischemia at the first seconds of VF. ATP content in myocardium is $5 \mu \mathrm{mol} / \mathrm{g}$ dry weight, the rate of ATP consumption is $0.5 \mu \mathrm{mol} / \mathrm{g}$ per second, and complete cycling of myocardial ATP pool occurs during $10 \mathrm{~s}$ [22]. There is reserve oxygen in myocardium (in the form of oxymyoglobin, oxyhemoglobin and physically dissolved 


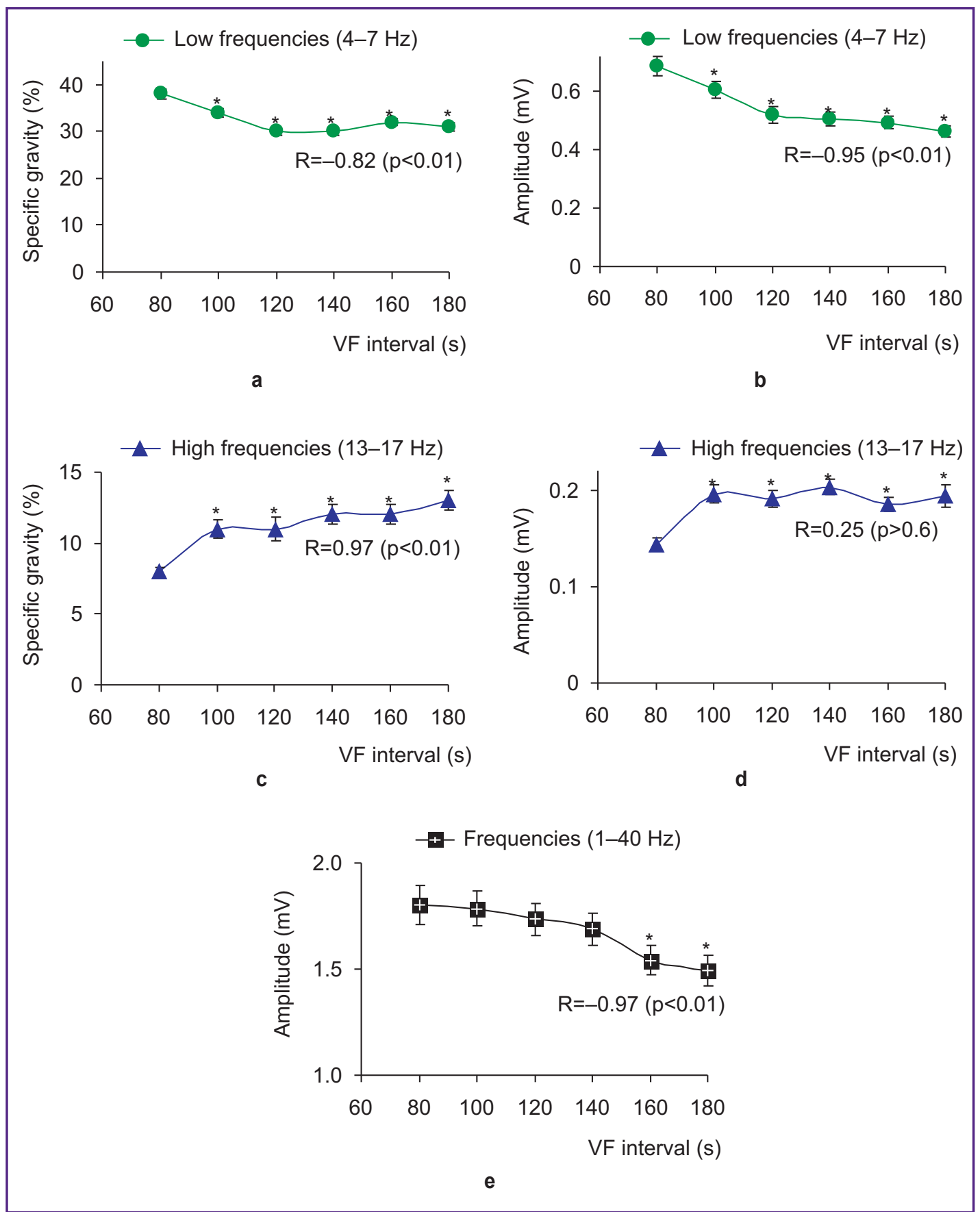

Figure 5. Dynamics of specific gravity and amplitude of various frequency oscillations during minutes 2-3 of ventricular fibrillation in the canine heart: (a), (b) 4-7 Hz oscillations; (c), (d) 13-17 Hz; (e) 1-40 Hz; M $\pm m ; n=50 ; ~ * ~ p<0.05$ compared to second 80 of ventricular fibrillation; R: correlation between duration of fibrillation and specific gravity (a), (c) and between duration of fibrillation and amplitude of oscillations (b), (d), (e)

oxygen) at the moment of total stopping of coronary blood flow under VF. Reserve oxygen is sufficient for 8-12 s under VF [23]. Myocardial activity at the first $20 \mathrm{~s}$ of VF is likely to be provided by consumption of myocardial ATP and by aerobic synthesis of ATP in the process of reserve oxygen utilization.

Domination of middle frequency oscillations (See
Figure 2 (a)) may reflect generation of synchronized APs in the frequency range of $8-12 \mathrm{~Hz}$, while domination of low frequency oscillations (See Figure 2 (a), (b)) may mirror generation of 4-7 Hz APs. Cardiomyocytes really generated APs of $10-11 \mathrm{~Hz}$ at minute 1 of VF [24] and APs of $5-7 \mathrm{~Hz}$ in the interval from the end of minute 1 up to minute 2 of $V F[24,25]$. Decline in the frequency of 




Figure 6. Amplitude dynamics of various frequency oscillations during minutes 4-10 of ventricular fibrillation in the canine heart: (a) 1-3 Hz oscillations; (b) 4-7 Hz; (c) 8-12 Hz; (d) 13-17 Hz; (e) 18-40 Hz; (f) $1-40 \mathrm{~Hz}$; $M \pm m$; $n=50$; * $p<0.05$ compared to the second 200 of ventricular fibrillation; $\mathrm{R}$ : correlation between duration of fibrillation and amplitude of oscillations

dominating oscillations should be associated with deficit of energy due to interruption of aerobic metabolism and transition to anaerobic glycolysis: glycolysis gives 2 molecules of ATP, while complete glucose oxygenation provides 36 ones [26].

According to Pasteur effect, ischemia stimulates multifold growth of glycolysis [26]. Evidently, glycolytic ATP is sufficient to keep up basic metabolism (maintaining myocardial structure and ionic gradients) at minute 1 of VF when organized activity is still preserved despite decrease in dominating oscillation frequency. This is comfirmed by the absence of decline in total amplitude (See Figure 4 (f)). With increased disorganization, the local electrical vectors increasingly oppose each other, thereby reducing total amplitude of ECG oscillations [27].

Two-fold broadening in the frequency range of dominating oscillations (from $4-7$ to $4-12 \mathrm{~Hz}$ ) reflects decrease in organized activity. Decline in frequency of APs generated by cardiomyocytes corresponds to 
domination of middle and low frequency oscillations on ECG (See Figure 2 (c), (d)). Purkinje fibers and working cardiomyocytes generated synchronized APs of $7 \mathrm{~Hz}$ at minutes 3-4 of VF; APs of $7 \mathrm{~Hz}$ and $4-5 \mathrm{~Hz}$ respectively at minutes 5-6; APs of $5-6 \mathrm{~Hz}$ and $2-3 \mathrm{~Hz}$ at minutes $7-8$; and APs of $4-5 \mathrm{~Hz}$ and $1-2 \mathrm{~Hz}$ at minutes $9-10$ of VF [24].

Discrepancy between the frequency of ECG oscillations and APs generated by cardiomyocytes reflects conduction block under the influence of ischemia at minutes 3-10 of VF. Ischemia leads to increase in extracellular potassium, cell depolarization, depression of maximal upstroke velocity and amplitude of AP, electrical disconnection of cells due to increased resistance of intercellular junctions - all this leads to conduction block $[28,29]$. Ischemic acidosis results in glycolysis inhibition and reduction of ATP content in myocardium [26]. Inhibition of glycolytic ATP synthesis is likely responsible for decline in amplitude of oscillations in all five frequency bands (See Figure 6). However, domination of low and middle frequency oscillations (See Figure $2(d)$ ) is indicative of the fact that decline in electrical activity occurs in "organized order" at minutes 4-10 of VF. Evidently, cardiomyocyte populations stopped their electrical activity when ATP exhausted in myocardium. This process can be associated with the growth of electrically mute zones in myocardium from 0 to $60 \%$ correlating with decline in oscillation amplitude at minutes $3-10$ of $\mathrm{VF}[30,31]$.

Canine heart rate (50-200 per minute) is higher but comparable to that of a human being (50-100 per minute) $[32,33]$. Frequency of VF oscillations in humans can be 500-600 per minute [34], so domination of middle frequency oscillations is possible in human VF. For example such VF frequency can be found in healthy man in the case of electric injury but it happens quite rarely [35]. Ischemic heart disease is the most frequent cause of VF [36] and oscillations of 4-6 Hz dominate at minute 1 of VF in such patients [37-40]. Consequently, the results of this paper can be used in algorithms for automatic detection of VF with dominant frequency structure.

Thus, VF is characterized by organized activity. It is possible to distinguish two ways of organized activity that have unequal functional significance in myocardium: functional integration of the heart with effective coordinated contractions corresponds to maximum synchronization in myocardium, while functional disintegration with ineffective uncoordinated contractions corresponds to less organized VF.

From the standpoint of myocardial synchronization, defibrillation should lead to restructuring of less organized VF into maximally synchronized coordinated contractions. Strong electric shock has been the one effective treatment for VF for several decades [1, 41]. Such a method of defibrillation can cause side effects: pain, myocardial injury, depression of contractions and cardiac arrhythmia, including ventricular refibrillation and atrial fibrillation [42]. Therefore, it is an urgent issue to search for weaker defibrillation stimuli, which could minimize side effects.

Organized VF activity is reproduced in each VF cycle, which provides self-maintenance of VF [43]. Sufficient time is needed for overcoming physiological inertia of VF. Myocardial mapping shows that defibrillation can take three consecutive cycles: the first and second cycles reflect sequential restructuring of $V F$, and the third cycle reflects withdrawal from VF [44]. Presumably, it would be worth-while experiment to restructure organized activity of VF and keep it in the direction towards coordinated contractions using relatively weak electrical stimuli, provided that stimuli are rhythmic organized during the sufficient interval of time.

Programmable serial stimulation revealed partial "capture" of myocardium by electrical stimuli under VF [45-47]. It should be noted that this stimulation was carried out using high and fixed amplitude and frequency of stimuli with no VF parameters being taken into account. According to the data obtained under analysis of myocardial excitability, increase in amplitude of stimuli between 1 and $20 \mathrm{~mA}$ leads to reduction of refractory period of the heart from 150 to $80 \mathrm{~ms}[48,49]$. VF periods of $70-100 \mathrm{~ms}$ correspond to VF frequencies of $10-15 \mathrm{~Hz}$ (See Figure $2(a)$ ). Therefore, there is the possibility of complete "capture" of myocardium in VF when using stimuli in the range of $1-20 \mathrm{~mA}$ and $5-10 \mathrm{~Hz}$.

An outstanding Russian physiologist Alexey A. Uchtomsky pointed out the possibility of rhythmic restructuring of excitable tissue [50, 51]. Rhythmic stimulation can increase synchronization of neurons and provoke an epilepsy seizure. Hypersynchronized paroxysmal activity of neurons corresponds to functional disintegration of the brain [52]. Synchronization of excitable cells is likely to have unequal functional significance in the heart and brain.

Conclusion. Ventricular fibrillation in the canine heart is characterized by dominant frequency structure of ECG. The most significant changes in the frequency structure occur at minute 1 of $\mathrm{VF}$ with transition from domination of high frequency oscillations $(13-17 \mathrm{~Hz})$ to domination of middle frequency ones $(8-12 \mathrm{~Hz})$ and then to domination of low frequency oscillations $(4-7 \mathrm{~Hz})$. At minutes 2-10 domination of low frequency oscillations is replaced by domination of low and middle frequency oscillations. Total amplitude of ECG oscillations shows no significant changes at minute 1 and significantly decreases at minutes $2-10$ of VF.

Dominant structure of ECG speaks of organized electrical activity in VF. Organized VF activity provides a good theoretical framework for searching a new method of rhythmic defibrillation using a series of relatively weak but rhythmic organized stimuli.

Study Funding and Conflicts of Interest. The study was not supported by any financial sources and there is no conflicts of interest related to the authors of this study. 


\section{References}

1. Gurvich N.L. Osnovnye printsipy defibrillyatsii serdtsa [The main principles of cardiac defibrillation]. Moscow: Meditsina; 1975.

2. Bockeria L.A., Bockeria O.L., Kislitsina O.N. Randomized clinical trials for prevention of sudden cardiac death: principles and total score. Annaly aritmologii 2010; 7(2): 5-14.

3. Hayashi M., Shimizu W., Albert C.M. The spectrum of epidemiology underlying sudden cardiac death. Circ Res 2015; 116(12): 1887-1906, http://dx.doi.org/10.1161/ CIRCRESAHA.116.304521.

4. Bockeria O.L., Akhobekov A.A. Sudden cardiac death: mechanisms and risk stratification. Annaly aritmologii 2012; 9(3): 5-13.

5. Abhilash S.P., Narayanan N. Sudden cardiac death historical perspectives. Indian Heart J 2014; 66(Suppl 1): S4S9, http://dx.doi.org/10.1016/j.ihj.2014.01.002.

6. Mathematical approaches to cardiac arrhythmias. Ann NY Acad Sci 1990; 591: 1-416.

7. Fenton F., Karma A. Vortex dynamics in threedimensional continuous myocardium with fiber rotation: filament instability and fibrillation. Chaos 1998; 8(1): 20-47, http://dx.doi.org/10.1063/1.166311.

8. Qu Z. Chaos in the genesis and maintenance of cardiac arrhythmias. Prog Biophys Mol Biol 2011; 105(3): 247-257, http://dx.doi.org/10.1016/j.pbiomolbio.2010.11.001.

9. Karma A. Physics of cardiac arrhythmogenesis. Annu Rev Condens Mat Phys 2013; 4(1): 313-337, http://dx.doi. org/10.1146/annurev-conmatphys-020911-125112.

10. Qu Z., Hu G., Garfinkel A., Weiss J.N. Nonlinear and stochastic dynamics in the heart. Phys Rep 2014; 543(2): 61162, http://dx.doi.org/10.1016/j.physrep.2014.05.002.

11. Qu Z., Weiss J.N. Mechanisms of ventricular arrhythmias: from molecular fluctuations to electrical turbulence. Annu Rev Physiol 2015; 77: 29-55, http://dx.doi. org/10.1146/annurev-physiol-021014-071622.

12. Huang J., Rogers J.M., Killingsworth C.R., Singh K.P., Smith W.M., Ideker R.E. Evolution of activation patterns during long duration ventricular fibrillation in dogs. Am J Physiol Heart Circ Physiol 2004; 286(3): H1193-H1200, http://dx.doi. org/10.1152/ajpheart.00773.2003.

13. Huizar J.F., Warren M.D., Shvedko A.G., Kalifa J., Moreno J., Mironov S., Jalife J., Zaitsev A.V. Three distinct phases of VF during global ischemia in the isolated bloodperfused pig heart. Am J Physiol Heart Circ Physiol 2007; 293(3): H1617-H1628, http://dx.doi.org/10.1152/ ajpheart.00130.2007.

14. Cheng K.A., Dosdall D.J., Li L., Rogers J.M., Ideker R.E., Huang J. Evolution of activation patterns during long-duration ventricular fibrillation in pigs. $A m \mathrm{~J}$ Physiol Heart Circ Physiol 2012; 302(4): H992-H1002, http://dx.doi. org/10.1152/ajpheart.00419.2011.

15. Barr R.C. The electrocardiogram and its relationship to excitation of the heart. In: Physiology and pathophysiology of the heart. Developments in cardiovascular medicine. Springer Science + Business Media; 1989; p. 175-93, http://dx.doi. org/10.1007/978-1-4613-0873-7_8.

16. Babsky E.B., Balanter B.I., Kireeva T.B., Macarychev V.A., Mezentseva L.V. Application of spectralcorrelation analysis to the study of ventricular fibrillation. Kibernetika (Moscow) 1972; 9-10(56): 44-51.
17. Tabak V.Y., Chernysh A.M., Nemirko A.P., Manilo L.A. The dynamics of spectral characteristics of ECG in cardiac fibrillation of the ventricles. Anesteziologiya i reanimatologiya 1980; 1: 71-74.

18. Newton J.C., Smith W.M., Ideker R.E. Estimated global transmural distribution of activation rate and conduction block during porcine and canine ventricular fibrillation. Circ Res 2004; 94(6): 836-842, http://dx.doi.org/10.1161/01. res.0000120860.01645.17.

19. Pandit S.V., Jalife J. Rotors and the dynamics of cardiac fibrillation. Circ Res 2013; 112(5): 849-862, http://dx.doi. org/10.1161/CIRCRESAHA.111.300158.

20. Mikhaylov S.S. Klinicheskaya anatomiya serdtsa [Clinical anatomy of the heart]. Moscow: Meditsina; 1987.

21. Koller M.L., Riccio M.L., Gilmour R.F. Dynamic restitution of action potential duration during electrical alternans and ventricular fibrillation. Am J Physiol 1998; 275(5 Pt 2): H1635-H1642.

22. Stanley W.C., Recchia F.A., Lopaschuk G.D. Myocardial substrate metabolism in the normal and failing heart. Physiol Rev 2005; 85(3): 1093-1129, http://dx.doi.org/10.1152/ physrev.00006.2004.

23. Gebhard M.-M., Bretschneider H.J., Schnabel P.A. Cardioplegia principles and problems. In: Physiology and pathophysiology of the heart. Developments in Cardiovascular Medicine. Springer Science + Business Media 1989; p. 655668, http://dx.doi.org/10.1007/978-1-4613-0873-7_32.

24. Huang J., Dosdall D.J., Cheng K.-A., Li L., Rogers J.M., Ideker R.E. The importance of Purkinje activation in long duration ventricular fibrillation. J Am Heart Assoc 2014; 3(1): e000495, http://dx.doi.org/10.1161/JAHA.113.000495.

25. Akiyama T. Intracellular recording of in situ ventricular cells during ventricular fibrillation. Am J Physiol 1981; 240(4): H465-H471, http://dx.doi.org/10.1016/0002-9149(80)90815-2.

26. Opie L.H. Substrate and energy metabolism of the heart. In: Physiology and pathophysiology of the heart. Developments in cardiovascular medicine. Springer Science + Business Media; 1989; p. 327-359, http://dx.doi. org/10.1007/978-1-4613-0873-7_16.

27. Caldwell J.C., Burton F.L., Cobbe S.M., Smith G.L. Amplitude changes during ventricular fibrillation: a mechanistic insight. Front Physiol 2012; 3: 147, http://dx.doi.org/10.3389/ fphys.2012.00147.

28. Lazzara R., Scherlag B.J. Cellular electrophysiology and ischemia. In: Physiology and pathophysiology of the heart. Developments in cardiovascular medicine. Springer Science + Business Media; 1989; p. 493-508, http://dx.doi. org/10.1007/978-1-4613-0873-7_23.

29. Kléber A.G., Rudy Y. Basic mechanisms of cardiac impulse propagation and associated arrhythmias. Physiol Rev 2004; 84(2): 431-488, http://dx.doi.org/10.1152/ physrev.00025.2003.

30. Venable P.W., Taylor T.G., Shibayama J., Warren M., Zaitsev A.V. Complex structure of electrophysiological gradients emerging during long-duration ventricular fibrillation in the canine heart. Am J Physiol Heart Circ Physiol 2010; 299(5): H1405-H1418, http://dx.doi.org/10.1152/ ajpheart.00419.2010.

31. Taylor T.G., Venable P.W., Shibayama J., Warren M., Zaitsev A.V. Role of $\mathrm{K}_{\text {ATP }}$ channel in electrical depression and asystole during long-duration ventricular fibrillation in ex vivo canine heart. Am J Physiol Heart Circ Physiol 2012; 302(11): H2396-H2409, http://dx.doi.org/10.1152/ajpheart.00752.2011. 
32. Janssen P.M., Periasamy M. Determinants of frequency dependent contraction and relaxation of mammalian myocardium. J Mol Cell Cardiol 2007; 43(5): 523-531, http:// dx.doi.org/10.1016/j.yjmcc.2007.08.012.

33. Milani-Nejad N., Janssen P.M. Small and large animal models in cardiac contraction research: advantages and disadvantages. Pharmacol Therapeutics 2014; 141(3): 235249, http://dx.doi.org/10.1016/j.pharmthera.2013.10.007.

34. Ivanov G.G., Vostricow V.A. Ventricular fibrillation and ventricular tachycardia - base position and diagnostic criteria. Vestnik Rossiyskogo universiteta druzhby narodov. Seriya Meditsina 2009; 1: 75-80.

35. Vostrikov V.A., Bogushevich M.S. Electrical injury: pathogenesis, clinical features, and treatment of electrical injury. Trudy filiala NII obshchey reanimatologii RAMN $v$ Novokuznetske 2001; 2: 3-16.

36. Myerburg R.J., Junttila M.J. Sudden cardiac death caused by coronary heart disease. Circulation 2012; 125(8): 1043-1052, http://dx.doi.org/10.1161/ CIRCULATIONAHA.111.023846.

37. Nash M.P., Mourad A., Clayton R.H., Sutton P.M., Bradley C.P., Hayward M., Paterson D.J., Taggart P. Evidence for multiple mechanisms in human ventricular fibrillation. Circulation 2006; 114(6): 536-542, http://dx.doi.org/10.1161/ CIRCULATIONAHA.105.602870.

38. Sánchez-Muñoz J.J., Rojo-Alvarez J.L., GarcíaAlberola A., Everss E., Alonso-Atienza F., Ortiz M., MartínezSánchez J., Ramos-López J., Valdés-Chavarri M. Spectral analysis of intracardiac electrograms during induced and spontaneous ventricular fibrillation in humans. Europace 2009; 11(3): 328-331, http://dx.doi.org/10.1093/europace/eun366.

39. Panfilov I., Lever N.A., Smaill B.H., Larsen P.D. Ventricular fibrillation frequency from implanted cardioverter defibrillator devices. Europace 2009; 11(8): 1052-1056, http:// dx.doi.org/10.1093/europace/eup159.

40. Bradley C.P., Clayton R.H., Nash M.P., Mourad A., Hayward M., Paterson D.J., Taggart P. Human ventricular fibrillation during global ischemia and reperfusion. Paradoxical changes in activation rate and wavefront complexity. Circ Arrhythm Electrophysiol 2011; 4(5): 684-691, http://dx.doi. org/10.1161/CIRCEP.110.961284.

41. Clinical cardiac pacing and defibrillation. Ellenbogen A., Kay G.N., Wilkoff B.L. (editors). WB Saunders Company; 2000.

42. Sowell B., Fast V.G. Ionic mechanism of shock-induced arrhythmias: role of intracellular calcium. Heart Rhythm 2012; 9(1): 96-104, http://dx.doi.org/10.1016/j.hrthm.2011.08.024.

43. Chen P.S., Wolf P.D., Melnick S.D., Danieley N.D., Smith W.M., Ideker R.E. Comparison of activation during ventricular fibrillation and following unsuccessful defibrillation shocks in open-chest dogs. Circ Res 1990; 66(6): 1544-1560, http://dx.doi.org/10.1161/01.RES.66.6.1544.

44. Zhou X., Daubert J.P., Wolf P.D., Smith W.M., Ideker R.E. Epicardial mapping of ventricular defibrillation with monophasic and biphasic shocks in dogs. Circ Res 1993; 72(1): 145-160, http://dx.doi.org/10.1161/01.RES.72.1.145.

45. Nanthakumar K., Johnson P.L., Huang J., Killingsworth C.L., Rollins D.L., Mselderry H.T., Smith W.M., Ideker R.E. Regional variation in capture of fibrillating swine left ventricle during electrical stimulation. J Cardiovasc Electrophysiol 2005; 16(4): 425-432, http://dx.doi.org/10.1046/ j.1540-8167.2005.40517.x.

46. Pak H.-N., Liu Y.-B., Hayashi H., Okuyama Y., Chen P.-S., Lin S.-F. Synchronization of ventricular fibrillation with real-time feedback pacing: implication to low-energy defibrillation. Am J Physiol 2003; 285(6): H2704-H2711, http:// dx.doi.org/10.1152/ajpheart.00366.2003.

47. Johnson P.L., Newton J.C., Rollins D.L., Smith W.M., Ideker R.E. Adaptive pacing during ventricular fibrillation. Pacing Clin Electrophysiol 2003; 26(9): 1824-1836, http:// dx.doi.org/10.1046/j.1460-9592.2003.t01-1-00276.x.

48. Alferness C., Bayly P.V., Krassowska W., Daubert J.P., Smith W.M., Ideker R.E. Strength-interval curves in canine myocardium at very short cycle length. Pacing Clin Electrophysiol 1994; 17(5 Pt 1): 876-881, http://dx.doi. org/10.1111/j.1540-8159.1994.tb01428.x.

49. Frommer P.L. Studies on coupled pacing technique and some comments on paired electrical stimulation. Bull N Y Acad Med 1965; 41: 670-680.

50. Uchtomsky A.A. Problema fiziologicheskoy labil'nosti (1939). V kn.: Sobranie sochineniy: V 6 t. T. 2 [The problem of physiological lability (1939). In: Collected works: In 6 vol. Vol. 2.] Leningrad: Izd-vo Leningradskogo gos. un-ta; 1952; p. 167-171.

51. Uchtomsky A.A. Ansambl' vozbuzhdeniya i elektroton (1941). Sobranie sochineniy: V 6 t. T. 6 [The ensemble of excitation and electrotonus. In: Collected works: In 6 vol. Vol. 6]. Leningrad: Izd-vo Leningradskogo gos. un-ta; p. 152-167.

52. Penfield W., Jasper $H$. Epilepsy and the functional anatomy of the human brain. London: I.A. Chuchill; 1954. 